\title{
DISCUSSION PIECE
}

\section{The use and abuse of participatory rural appraisal: reflections from practice}

\section{Andrea Cornwall • Garett Pratt}

Accepted: 31 August 2009

\begin{abstract}
Over the course of the 1990s, donor enthusiasm for participation came to be institutionalized in a variety of ways. One particular methodology-Participatory Rural Appraisal (PRA) — came to enjoy phenomenal popularity. New aid modalities may have shifted donor and lender concern away from the grassroots towards "policy dialogue." But "civil society participation," "social accountability," and "empowerment"- some of the issues PRA grapples with - retain a place in the new aid discourse. PRA and its variants also continue to be used by government agencies, non-governmental, and community-based organizations in local-level assessment, planning, monitoring, and evaluation, as well as in national-level poverty assessments. It has sometimes been conflated, by donors and critics alike, with doing "participatory development," and has elicited critiques that often go far beyond the bounds of the methodological. Yet these critics have tended to be academics with little experience as practitioners or facilitators. In this article, we draw on an action research project with PRA practitioners. We explore, through their critical reflections, some of the conundrums and contradictions faced by those who were active as PRA practitioners in the early 1990s. We suggest that the story of PRA's success and of subsequent concerns about "abuse" and "misuse" by mainstream development institutions offers broader lessons with continued salience for development.
\end{abstract}

Keywords Participation, PRA, Community development, Development organizations

\author{
Abbreviations \\ IIED International Institute of Environment and Development \\ PRA Participatory Rural Appraisal
}


A. Cornwall (email)

Department of Anthropology, University of Sussex, Brighton, East Sussex, BN1, United Kingdom

Email: A.Cornwall@sussex.ac.uk

G. Pratt

Canadian International Development Agency, 200 Promenade du Portage, Gatineau, Quebec, K1A 0G4, Canada

Email: garett.pratt@international.gc.ca

\section{Author Biographies}

Andrea Cornwall is Professor of Anthropology and Development in the School of Global Studies at the University of Sussex, Brighton, UK, where she works on the anthropology of democracy, sexualities, women's rights, and masculinities. Recent publications include Democratizing engagement (Demos, 2008), The politics of rights: Dilemmas for feminist praxis (co-edited with Maxine Molyneux, Routledge, 2008), and Spaces for change: The politics of citizen participation in new democratic arenas (co-edited with Vera Schattan Coelho, Zed Books 2007).

Garett Pratt is a Senior Development Officer in the Canadian International Development Agency. A development studies specialist, with an MPhil in Development Studies, he has lived and worked in a number of developing countries, and conducted research on institutionalizing participation and human rights. He is co-editor of Pathways to participation: Practitioners' perspectives on PRA (co-edited with Andrea Cornwall, Intermediate Technology Publications, 2005).

\section{DISCUSSION PIECE}

The use and abuse of participatory rural appraisal: reflections from practice 


\section{Introduction}

From origins in the practices of a small cluster of development professionals in the late 1980s, Participatory Rural Appraisal (PRA) spread at an astonishing pace across the world over the course of the 1990s. Associated in some countries with local NGOs and in others with foreign development agencies, PRA came to acquire a global feel by virtue of a repertoire of techniques with which it became identified wherever practiced. Advocates resisted the specifics of definition and encoding practice in manuals, preferring instead to put forward slogans, principles and injunctions, or descriptions that might embrace any number of possibilities. Absalom et al., for example, describe PRA as:

A family of approaches and methods to enable rural people to share, enhance, and analyze their knowledge of life and conditions, to plan and to act. (Absalom et al. 1995, p. 1)

The popular image of PRA as people playing with beans and drawing pictures is one often used by critics to disparage its use. The use of visualization may be its most distinctive quality, but this image also evokes other features associated with the approach. PRA is something that is often done by groups, it can be fun and it works with people's creativity to engage their analytic skills. Although its critics are many (see, for example, Cooke and Kothari 2001), its use has had a range of effects on development. These, however, are sometimes overlooked partly because PRA has eluded attempts to define, prescribe and bound it as a methodology or form of practice. Despite-or perhaps because of-this, PRA has seemed more vulnerable than any other methodology to what practitioners call "abuse" and what critics regard as shoddy practice.

In this article, we draw on an international action research project, Pathways to participation, which involved empirical research on trajectories of PRA practice in Kenya, Mexico and Nepal and a symposium that convened practitioners who had been closely involved with the take up and spread of PRA internationally, to reflect critically on what happened as PRA became taken up with enthusiasm by development actors of all descriptions (Cornwall and 
Pratt 2003). While PRA has been subject to numerous academic critiques, these are rarely based on the perspectives of those who have been engaged in actual participatory development practice - and suffer from consequent limitations, most commonly the conflation of "PRA" with "participatory development" or that take one of its myriad manifestations and reify it into the basis for critique (see, for example, Mosse 1995; Kapoor 2005). The aim of this paper to reflect, from the vantage point of a present in which academic talk about PRA has subsided but practice certainly has not, about what broader lessons might be drawn from this experience.

In doing so, the scope of analysis is limited to a close examination of the meanings and practices associated with PRA. By specifying our focus in this way, we hope to suggest not only that the conflation of PRA with participatory development is problematic, but also that the category PRA is unstable, polyvalent, and reflects diverse possible practices. "Participation" has come to embrace a plurality of normative and ideological positions, from communitarian impulses towards neo-liberal "do it yourself," "community-driven" strategies, to radical democratic notions of expanding the boundaries of the political, all of which have histories (Cornwall 2006) and all of which imply different purposes to which technologies like PRA may be put.

Today's development actors are more concerned about how to cope with soaring budgets and decreasing numbers of people to disburse them, with activism on the global stage rather than project-based action at the local level, and with new modalities of aid that operate at such a remove from the everyday lives of poor people that methodologies like PRA may now seem virtually irrelevant. Although the rhetoric of the need to involve "the poor" has not abated, donor and development studies attention has returned to the macro level and to new aid instruments that focus less on public engagement than financial management. As today's international NGO practitioners grapple for ways of assessing impact and applying their "rights-based approaches" and as today's donors bemoan their estrangement from the field, there may indeed be something to learn through critical retrospection.

The article begins with reflections on old methodological debates within development studies that took a new twist with the arrival of participatory methodologies such as PRA. It goes on to contextualize the analysis that follows in a brief account of how and why PRA emerged, and how it subsequently came to be shaped and used. We then explore practitioners' perspectives on the rising concerns with "abuse" that came to be a topic of intense discussion among PRA 
practitioners over the course of the 1990s. These concerns reached their height with the "scaling up" of use of PRA-style methods in the World Bank's Consultations with the poor (World Bank 2000/1; Narayan et al. 2000; Brock and McGee 2003), in Participatory Poverty Assessments, and in large-scale government programs (Thompson 1995). They continue in the use of these methodologies for "empowerment," "social accountability," and rights-based approaches, as well as for planning, monitoring, and evaluation more generally. We discuss the broader epistemological and methodological implications of these concerns, before returning to reflect on the broader issues that this discussion raises for the use of participatory methods in development.

\section{Quandaries of quality}

The quandary of quality has long been a concern among those working on popular participation and participatory research. It emerges in Sherry Arnstein's (1969) classic account of the politics of participation in late 1960s America, and Robert Chambers' (1974) memorable critique of the uses of participation in post-colonial Africa. Quality has been a live issue among PRA's pioneers and advocates. A series of statements signed by a string of PRA practitioners testify to how broadly concerns about "abuse" of participation were shared within the "PRA community" (Absalom et al. 1995, Adhikari et al. 1997 "Going to scale with PRA: Reflections and recommendations" mimeo; Praxis, n.d.). Since the early 1990s, articles in the International Institute of Environment and Development's practitioner-focused journal Participatory Learning and Action have raised a host of critical questions about the meanings and purposes of "participatory research" in practice.

Captivating stories from experiences all over the world, along with catchy slogans with powerful messages, were used over the 1990s to promote PRA by its pioneers and the legions of trainers who came to work alongside them. Today's tales are less proselytizing than cautionary. One hears of PRA being used so extensively in local level planning and assessments that it was likened by one development worker to carpet bombing (Robert Chambers, personal communication); of villagers organizing advance parties to meet eager PRA teams with copies of diagrams they had drawn for the previous PRA team; and even of one village who had the foresight to construct a weatherproof social map for visiting PRA-ers. Anecdotes are told of 
consultants who do their "PRAs" in an afternoon by rounding people up, splitting them into groups and giving each group a diagram to complete-compiled into a report, there is little to distinguish these from the longer, slower processes of iterative learning undertaken by other practitioners. Apocryphal as these accounts may appear, they attest to the concern about the "abuse" of participatory methodologies that has come in the wake of commitment to "scaling up" and "scaling out" that was part of the mainstreaming agenda (Gaventa 1998; Kanji 2003).

Critics have long fired their shots at PRA. Mainstream positivists have been dismissive of a form of practice considered impressionistic at best. Would-be allies such as anthropologists and community development workers have been barely more sympathetic to something regarded as a "quick and dirty" substitute for "proper" research and engagement (Richards 1995; Cornwall and Fleming 1995; Cooke and Kothari 2001). For years, practitioners and advocates tended to close ranks and defend PRA against these waves of criticism, shrouding the lively auto-critique that was part of internal debates from external view. ${ }^{1}$ But as the 1990s wore on, a different mood began to ripple through the broad networks of people associated with PRA. Writing in 1997, Robert Chambers pinpoints the concerns that were circulating among key PRA pioneers and trainers, and that were only to become more acute:

Most donor agencies, governments, universities, training institutes, and NGOs continue to promote and practice business-as-usual with top-down blueprints, packages, targets, and teaching. Only the language has changed. Many adopt the new rhetoric of participation; few change what they do. At the same time, on a vast and increasing scale, donors and governments demand and require participation and that PRA be used, more and more universities and training institutes seek to teach PRA in the classroom; many NGOs assume that NGO status alone enables them to be good PRA practitioners; and consultants

\footnotetext{
${ }^{1}$ The most concerted and best-known critique of PRA, published in the book The tyranny of participation (Cooke and Kothari 2001), makes a number of useful observations about the paradoxes of PRA and participation. However, the book has served rather more as an irritant than as useful food for thought for PRA's practitioners - in part, because internal debates had long wrestled with often more sophisticated versions of the questions that were posed by the academics who contributed to it, many of whom were judged by practitioners to have scant experience and understanding of PRA.
} 
co-opt the label without the substance or the spirit. The result is abuse and malpractice on a massive scale. (Chambers 1997, p. 8)

For many, PRA's success came to be entangled with a sense that for all that has been achieved, something has gone awry; or, as an NGO manager and PRA practitioner in Kenya observed, "we're in a mess - everyone is doing something and calling it PRA."

Our analysis in this article attempts to situate this "mess" within an analysis of what exactly "PRA" has come to consist of-which, as we show, is less a single approach than a heterogeneous collection of practices with some family resemblances. This, we argue, has significance not just for the salience of generalizing critiques but also for any attempts to arrive at criteria for "good quality" PRA practice. In what follows, we seek to situate competing versions of PRA, against which complaints about "bad" PRA practice are framed, within the broader dilemma of whether it is possible to arrive at any single version of what "good" participatory practice might look like. We begin by taking a look at the critique from "within"that of people who practice, promote, and commission PRA - and at the concerns that it raises for practice. We go on to analyze different perspectives on the nature of the problem, and the kind of solutions that might be needed, and conclude with reflections on what all this might mean in the changing world of today's development practice.

\section{A diversity of practice: The spread of PRA}

From a practice that had its origins in a handful of Kenyan and Indian villages in the late 1980s, PRA is now taught on university courses, regarded as a "must have" by development workers in many parts of the world, and used by a huge variety of development organizations. Today, few countries remain untouched by some variant or other of PRA practice, which has come to be used in a dazzling array of settings and for an ever-expanding range of purposes. Slotted into mainstream development or providing a challenge to entrenched attitudes and ways of working, PRA has become part of everyday development practice.

The story of its rapid expansion is germane to our analysis. PRA appeared in the late 1980s, born out of a bricolage of methods borrowed from agro-ecosystems analysis and 
anthropology, fused with some of the principles of participatory research and elements of the practice of rapid qualitative enquiry, popularized in the 1980s as Rapid Rural Appraisal (RRA). Chambers (1992) talks of the coming together of these different influences as a "braided stream," flowing together into this new methodological hybrid. In practice, however, some elements continued to be more salient and influential in shaping practice than others. The imprint of RRA was perhaps the most significant and enduring, while the influence of anthropology has arguably diminished to the point where all that remains are techniques that are now better known as "PRA methods" than as part of an anthropological toolkit. ${ }^{2}$

The hallmark of RRA was its modest intentions. Dubbed "organized common sense" by Chambers (1983), it was eminently practical and admirably pragmatic. Simple visual tools and semi-structured interviews, guided by collectively generated checklists, provided ways of finding out fast and for building rapport and respect. They could be learnt by almost anyone in a matter of days. "Appropriate imprecision" and "optimal ignorance" were the watchwords of RRA: there is no need, and no time, to measure things exactly or to know everything about what is going on, just enough to be able to take sensible steps towards making things work. Rather than gathering data and taking it away for analysis, RRA emphasized iteration ("learn as you go"), the ongoing crafting and adjustment of checklists and analyses, and rapid report writing, finished while still in the field and verified with participants there and then.

Initial distinctions between RRA and PRA turned on the "participatory" nature of PRA. Instead of researchers drawing diagrams, analyzing, making recommendations, PRA sought to engage participants in producing their own data, analyses, and solutions. In practice, things were rather more blurred. There were RRA practitioners who had been involving participants in diagramming for some years. And rather than simply enabling participants to do their own research in their own ways, PRA facilitators offered a set of templates and processes through which participants' knowledge and preferences were mediated.

\footnotetext{
${ }^{2}$ See Pelto and Pelto's (1978) guide to anthropological methods, which includes variants of many of the techniques now known as "PRA methods," from wealth ranking to listing, ranking, and scoring.

${ }^{3}$ Using these methods well called for skills that early proponents were not so quick to recognizeperhaps, as a leading trainer from this era reflected, because few of them had a background in the qualitative social sciences themselves (Guijt 2003).
} 
Coupling the pragmatic attitude of RRA with an approach that emphasized "handing over the stick" to local people for them to take the lead in analyzing, planning, and acting, PRA offered a powerful and accessible alternative to conventional development practice. Within a few years of the birth of PRA, RRA had become a term that was often used with disparagement, evoking a process controlled and focused by outsiders, too quick, and not followed up. The label "extractive" was often used, in contradistinction to "empowering" PRA. In effect, RRA became an oppositional category. It was used to define all the more sharply the newness and goodness of PRA, even when there was little new about it. People either did the real thing, PRA, or it was "just" RRA.

\section{Rising demand, expanding possibilities}

By the early 1990s, the small network of academics and practitioners who pioneered PRA was battling to keep up with rising demand from development organizations for training. Trading off depth for the numbers of people exposed to PRA, "familiarization" sessions consisting of as little as a few hours brought the message to quarters that lengthy training courses would never have reached. PRA was taken up and used across an ever-expanding range of contexts. In the spirit of innovation, those who developed PRA defined it as a practice that was constantly evolving and infinitely accessible. PRA had properties unlike any other methodology. It was capable of giving rise to an infinite number of adaptations, flexible enough to accommodate any issue, any situation, any practitioner, so simple that it could be picked up by anyone, so effective that it could serve any purpose. PRA spoke to the frustrations and hopes of a diverse spectrum of development actors, offering them what they wanted and needed. It spread so far and so fast precisely because of the breadth of its appeal and its elastic possibilities.

From a marginal, and often derided, practice, PRA fast became a valuable commodity. Champions of PRA networked, levering pressure on organizations and government departments to organize training courses for their staff. Many of the most influential first generation trainers roundly resisted pressures to codify practice and standardize methodological procedures, eschewing manuals and recipe-books. Some trainers provided a structured repertoire of methods. 
Others simply offered trainees an experience that they were invited to adapt and use as they saw appropriate, and enjoined them to "use your own best judgment at all times."

While the methods themselves were sometimes regarded as the magic ingredient that would work irrespective of how people came to learn about them, the trainers' style of delivery and emphasis inevitably left an imprint on how PRA was used in practice. Different messages, different methods of instruction, different expectations: all gave rise to some of the considerable variety of practices that came to be associated with "PRA." Diversity continued to be fostered through the unregulated and imperfectly informed market for training services, as the people commissioning training often had little sense themselves of what it was they wanted their staff to learn, or what distinguished one trainer's presentation of PRA from another's.

"It was like learning a new fashion trend," wrote Regis Gwaba (2003, p. 88) of her first encounters with PRA. But, what exactly was spread during this exhilarating period? Meera Kaul Shah, who played a key role as one of PRA's pioneers in introducing PRA around the world comments:

The speed with which the use of PRA methods spread around the world was amazing. I wish I could say the same for participatory processes. Soon it became fashionable to say that "we have done a PRA" or that "we use PRA." In many ways, I feel this spelt the death of PRA. (Shah. 2003, p.192)

Fifteen years later, PRA trainers and consultants number in the thousands. Some left government and NGO jobs to set up lucrative consultancies of their own, others delivered training in PRA as part of their jobs in government and international development organizations, others still were able to embed the practice of PRA into the organizations and departments that they came, over time, to run.

Skeptics and cynics may have been vindicated by the excess of "bad practice" that has come in the wake of enthusiasm for PRA (Richards 1995; Mosse 2001). Yet many critics grudgingly accept the need to incorporate things participatory in some way or other in what they do, and some have come to adopt elements of PRA as a means of securing funding or legitimacy. For those who struggled on the margins of development to advocate for and defend a form of practice that promised so much, the fantastic success of PRA ought to be a cause for celebration. 
What, then, are we to make of the complaints voiced by practitioners that things have somehow gone wrong?

\section{Complaining about quality}

Reflecting on the trouble with PRA, practitioners highlight a range of ills, from the mechanistic use of methods within unchanged development institutions to inconsistencies between what is claimed and what is done. Listening more closely to these complaints, however, it becomes clear that people are bemoaning rather different things. For some, what was at issue was the misuse of PRA: for them, PRA “done properly" could deliver its promised goals. What exactly "doing PRA properly" might entail was in itself deeply contested; the very practices that some

associated with "bad practice" were, to others, essential ingredients for "good practice." At a deeper level, disagreements over how to do PRA reflect a diversity of assumptions about development that frame what PRA is used for.

The more we heard practitioners' critical reflections on PRA, the more we felt that there was something rather distinctive about them: something quite different to the kinds of things we were hearing from those who had simply heard about, or perhaps observed, PRA, such as many of those associated with the Tyranny of participation critique (Cooke and Kothari 2001). What was different was not the nature as much as the object of their criticism. Critics who lack familiarity with the practice of participatory methodologies tend to represent PRA as a singular methodology that suffers uniformly from particular defects - whether lack of "objectivity" and rigor, or shortcomings in terms of social analysis. What we were hearing described different, and sometimes directly opposing and almost mutually exclusive, versions of what PRA is and ought to be. And, while these different PRAs had some family resemblances, they were in some respects completely different kinds of practice gathered for convenience under a common label.

\section{Doing it right: The contested ingredients of "good practice"}


The nature of the complaints that people make about the "abuse" of PRA attests to diversities within the "PRA community" that are rarely acknowledged, yet vitally important to recognize. For many people, PRA is defined by its distinctive visualization methods: tools such as maps, matrices, calendars, rankings, and scorings, done by groups of people and accompanied by a discussion are at the heart of the methodology. For some, the problem is an over-emphasis on these methods; as a Kenyan critic put it, "there's nothing about attitude and everything about the tools." For them, what is at issue is that PRA methods have become like a questionnaire survey or focus group: another tool to add to the arsenal of conventional research techniques. "Bad practice" comes to consist of the use of the same strings of methods in pre-designed sequences irrespective of the context, applications that are judged "mechanical" or even regarded as empty rituals. A Nepali practitioner voiced a commonly heard critique,

They think that PRA is a good thing and so they apply some tools, and then they leave back, and after some time there is nothing. It is PRA for PRA... They want to show that they have done so many PRAs in so many villages. And sometimes it has become ritual... (Pratt 2001, p. 17)

But some practitioners identify the opposite problem. Their concerns center on what they see as sloppy practice: not cross-checking information, not using a range of methods with a range of actors to triangulate findings, or not producing a "Community Action Plan" at the end of a PRA exercise to formalize consensus. They argue that the language of "use your own best judgment" encourages a lack of rigor. They complain that people leave out important techniques rather than undertaking a "full PRA." And they worry that the emphasis on attitude and behavior detracts from producing a trustworthy analysis on which to base plans for action or policy recommendations.

For some, PRA is a "way of doing business"; for others it is a "way of life." There are those practitioners who go so far as to argue that "good PRA" can and does consist of displaying the correct attitudes and behavior, without necessarily using any kind of "methods" to interact with people. An experienced Kenyan practitioner, who has used PRA in different international NGOs since the early days, commented: 
People think they are tools - they're not. The most important thing about PRA was going in and listening ... Just getting staff members to go to peoples' houses and listening to them was the revolution. (Cornwall et al 2001, p. 14)

If what PRA is serves as a source of such diverse views, what it is not also becomes a marker of some of these differences. Sometimes people express their own confusion about how to set the boundaries around PRA. They do not know whether to call practice that does not live up to their approval an "abuse" of PRA or to say that it is not PRA at all. For example, an influential practitioner, trainer, and networker in Nepal argued that if PRA is not used to pursue the alleviation of poverty for the poorest, then "that is not PRA—or I don't know, maybe it is PRA but not the kind of PRA we want." It is not uncommon to hear practitioners labeling practices they do not approve of as not being "real PRA." For others, there is genuine uncertainty as to whether what they are doing can be called "PRA" or not. In Kenya, for example, a fieldworker started to talk about his training in PRA and describe questionnaires and interviews, and then stopped to wonder "I don't know - is that PRA?" Just as "RRA" became a term of disparagement, in some quarters "PRA" came to be yesterday's label as practitioners professed to be doing "PLA" (Participatory Learning and Action) - a label that emerged when IIED, one of the leading institutions promoting PRA, changed the title of its journal RRA Notes to PLA Notes, amid cautions that the result would be a proliferation in the use of the term "PLA" as the latest fashion. ${ }^{4}$

One focus for complaint from all sides, and one that reflects very different ideas and ideals, is the duration of PRA processes. It is common for practitioners to complain about things being too "rushed," or even to regard the word "rapid" with suspicion. Organizations arrive and demand that people participate in PRA exercises at short notice, at inappropriate times of day or of the year. Criticism is leveled at them for doing hasty analyses, for not giving people enough time to reflect and learn and be "empowered," for not working at people's own pace. But one also finds people criticizing PRA for being too slow, for taking too much of people's timeusually with no recompense-disrupting their lives and livelihoods. A chief in Kenya, for example, complained that given the time it took for him to join in a PRA exercise in one village, it would take years to cover the whole district. A practitioner who later became a donor in one of

\footnotetext{
${ }^{4}$ We avoid the use of "PLA" in this piece, for this reason.
} 
the agencies who lent considerable support to the expansion of the use of participatory methods in development, Sida, Katja Jassey reflects, "What was so bad about, for example, Rapid Rural Appraisal (RRA) that we had to drop it from programs like the one I was involved in? PRA takes a lot of valuable time from hard-working people" (Jassey 2003, p. 96). An Indian NGO strove to develop simpler methods that would produce information faster, without taking so much time from local women. And a project manager in Nepal asked why anyone should wait two years for PRA discussions to produce the outcome that education is a priority, when it is obvious that education should be available to everyone and the school could have been built in the meantime (Pratt 2001, p. 32).

Particularly for practitioners new to PRA, the practical elements of "doing it right" are the focus of much debate. But as practitioners become more comfortable with facilitating the tools, or listening in a way they have not before, they start to raise a different level of questions about what it means to do "good" PRA.

\section{Doing it for the right reasons: What is PRA for?}

Many complaints and stories about bad practice do not focus on how PRA was done as much as they reflect a criticism of the purposes for which it is used. Some practitioners view PRA as a means for generating and analyzing data, as a direct substitute for other forms of research such as questionnaire surveys. A senior manager in a UN project in Nepal, for example, argued that,

Especially in the beginning of the program... we need the baseline to monitor or assess the effects of the project... To collect that information, projects mostly take a sample, then use a questionnaire survey. It doesn't come up with a good report. People get lost in data collection. This approach is still going on. We tried to introduce PRA, because it is very fast, very informative, and works case to case. It is very specific to a certain area, a specific place, a specific community... It gives quick results. You can have a lot of information and it is more than $90 \%$ reliable... (Pratt 2001, p. 27) 
Many more practitioners view the purpose of PRA as "empowerment" of some kind. Their understandings of empowerment are often implicit, but range from thinking of personal empowerment (PRA gives participants confidence in expressing their views in public meetings, or in the knowledge they have); to more collective forms of empowerment (people see the resources and potential in their community, or gain the courage to make approaches to authorities with plans or demands). Practitioners complained that most PRA practice does not live up to claims that it is empowering, particularly in a collective sense. They argued that it is just used for "extracting" information, and that this application is wrong. As a manager in an international NGO influential in introducing and supporting PRA in Nepal, said, "the real empowerment... hasn't come because it has just been used to explore, an extractive tool." (Pratt 2001, p. 40)

In Kenya, a long-standing practitioner now based in a donor organization contended that “as more people come to use PRA they're reducing it to a mechanism or one-off intervention" that does not have any meaningful transformative effect on the participants. Many Mexican development professionals characterize PRA as a methodology imported from Britain and the United States, and void of any focus on the politics of transformation. Some dismiss PRA for this reason. Others speak of "Mexican PRA" which has incorporated ideas behind Mexican participatory methodologies, such as autogestion (self-determination), educacion popular (informal education), and concientizacion (consciousness-raising) (Moya and Way 2003).

For some practitioners, an important aim of PRA is to transform the professionals who fund or facilitate development. A concern for them is the way that many development professionals continue to practice PRA without displaying or adopting the "desired" or "right" attitudes and behaviors. For some, the problem is that practitioners display the right attitudes and behavior in their interactions with other professionals and in how they represent their own practice in rhetoric or writing, but do not display them when doing PRA with community members. For others, it is the other way round; people are nice enough when they are in communities, but revert to being dominating and insensitive in their offices or homes. A Nepali practitioner observed:

People say very beautiful things, beautiful words. People write very beautiful phrases and sentences using participatory approach of development... But while looking back to him or 
her and these activities at office, maybe at home, the approach is not being practiced. (Pratt 2001, p. 51)

One long-standing Kenyan participation practitioner highlighted these contradictions, complaining that "one minute you are this very concerned, sensitive, development practitioner who is keen to listen to people, and the next minute you scream at the driver or the office staff, or the way you treat your wife or spouse" (Cornwall et al. 2001, p. 15).

These types of complaints take us towards very broad, nebulous explanations of the purpose of PRA, that frame it as much more than an isolated practice or event that fulfils a specific purpose. Many practitioners and advocates in Nepal understand PRA as "a way of life," by which they mean that PRA is a matter of practicing the right attitudes and behavior in all interactions in life. An Indian researcher who uses PRA argued that "PRA is yoga"-a process of personal transformation. In Kenya, we found people gave similarly broad definitions. For example, one person said that, "PRA is anything that will enhance more people to get involved, and will allow more people to give their ideas." These definitions are all so broad that almost anything could be included. Conversely, "bad PRA practice" could include everything from project-based development, to a professional's decision to wear urban clothes or sunglasses in a rural setting, to people's personal relationships with their families.

There is often a moral tone to criticisms raised by practitioners about the purposes for which others use PRA. A trainer in Kenya, frustrated by the superficial way that PRA was taken up by her colleagues, said, "it's a kind of password because you think it will be funded and it looks like you're up to date on what's happening in the world." Nepali practitioners roundly condemned people who used PRA as a way of demonstrating that they are "in fashion" in development circles. Given the lucrative market for PRA practice that emerged from the late 1990s onwards, some practitioners felt that PRA practice motivated by personal profit is somehow inherently substandard. Similarly, practitioners expressed suspicion of others' practice if their motivation seemed to be career advancement in riding the PRA wave right to the heart of the development mainstream.

\section{Thinking through quality in context}


Any definition of PRA that relies on some essential element, whether it is visual diagramming, particular attitudes or behavior, is likely to exclude many practices people understand as PRA. Critical reflections on PRA begin from very different understandings of what is being evaluated. Is it an approach? A set of methods? A methodology? Is it doing a social map? Is it a set of attitudes and behaviors? Is it a philosophy? Is it a management tool? Is it a set of values? Is it qualitative research? Is it a data-gathering tool? Is it empowerment? Is it participation? Is it defined by the purpose of those who use it? Is it three days long? Is it an ongoing process? Is it a way of life? Is it creating a community action plan? Any discussion of what good quality PRA might consist of, and how to work towards it, should acknowledge the empirical reality that this diversity of views exists. But if this is the case, how can anyone make a judgment as to the "quality" of what is done in the name of PRA?

Part of the difficulty in defining and judging quality is accounting for the very different uses to which people put PRA. Different dilemmas for assessing "good quality" practice arise when it is used to generate data for decision making by development project managers, to raise the consciousness of marginalized people leading them to take action, to create research outputs, or to live one's life in a way that improves one's relationships with other people. Clearly, a onesize-fits-all approach to determining what might count as "good" or "bad" would do little to help where one set of criteria might directly contradict others.

Along with the "use your own best judgment" philosophy of PRA comes a tendency to put the practitioner at the center of both decision making and responsibility for the form that PRA takes, and thus its "quality." Yet PRA processes are terrains of contestation in themselves: arenas in which different understandings of purpose, political agendas, visions, and versions of participation are negotiated and acted out. People may engage in the process for entirely different reasons, subscribing to a common vision and pursuing other ends within it. Many practitioners are not completely transparent about their objectives at the outset, for example pursuing a "Trojan horse" strategy, using a request for information provision on the part of a donor to open space for a process of participation that might not have been on the donor's agenda. Or the "real" objectives of a PRA might be unspeakable for other reasons.

Take, for example, a situation that became commonplace as PRA spread and became "scaled up," in which PRA comes to requested by donors as a tick-box procedure. The pragmatic 
practitioner may find her/himself making limited, and thus acceptable, requests for changes to terms of reference rather than seeing the contract go to one of the legion of competitors who are willing to do what a donor asks without challenge or question. Strategic accommodations make the best of a less than ideal situation, but also involve compromises that can easily be regarded as "abuse." In view of what is often limited space for negotiation in donor regimes, experiences that seem at first sight to be examples of the worst possible practice — such as rounding a few people up under a tree and giving each group a diagram to produce a "PRA report" in an afternoonmight be seen as a more honest way of working. If the donor has no interest in supporting anything beyond the particular project they are "doing a PRA" to legitimate, why waste more than half a day of people's time?

In the midst of all this contestation over the objectives of PRA, even the most skilled and committed facilitators may find themselves with a lonely and uphill struggle. Wilhelmina Pelegrina vividly captures some of the questions and dilemmas practitioners have been faced with:

Am I too idealistic? Am I too much of a purist? Do I still believe in participation? Shall I move with the tide and satisfy the demand for PRA and PRA training? Or shall I stand firmly for what I believe in? What do I believe in? Am I the only one asking these questions? (Pelegrina 2003, p. 143)

As we talked to those who conduct and commission PRA, we were struck by the extent to which people looked to others as the source of the problem: to donors, for not being clued up enough to know what to ask for, or so impatient that they wanted things to be done yesterday; to other practitioners for cutting corners and making a fast buck; to governments for not being serious about public consultation and using PRA as window dressing; to international consultants for making their living from the quick-and-dirty and leaving nationals to pick up the pieces; to NGOs for pushing their own agendas, be they faith-based or political; to consultants greedy for business and unwilling to share trade secrets that might undermine their next contract; to the unscrupulous who rush and fake....the list goes on.

Efforts to stem some of these effects included codes of conduct, information for donors to encourage them to be more prudent in their commissioning - such as a checklist of questions to 
ask of would-be participatory facilitators produced by the Bangladesh participatory methodologies network - and attempts to institutionalize linking PRA-based research and consultation into longer-term processes of participatory planning, monitoring and evaluation, and transformation. These were strategies developed and promoted by participation practitioners themselves, in attempts to improve the credibility and depth of participatory practice. Most importantly, the residual quality that held these strategies together was a common commitment to precisely the kinds of ideals about which Wilhelmina Pelegrina speaks, and they largely recognized the power issues at stake. It is all too easy for academic critics to be cynical about these ideals, without recognizing the importance of the normative dimensions of practitioner attempts to define their own practice.

\section{Conclusion}

Although the days of the "PRA boom" are over, and the debates about "scaling up" have shifted from the use of methodologies for consultation to questions of representation and voice in new arenas for "civil society" and citizen participation (Cornwall 2004; Cornwall and Guijt 2004), PRA continues to be used and taught in many countries. As we have shown in this paper, "PRA" is a term that has become filled with a rich spectrum of meanings and practices. There are, as we note at the beginning, some family resemblances between these forms of practice, but only at a very residual level.

Many of the attempts people have made to stem the flood of "bad practice" have rested on a particular reading of what PRA is or ought to be. Yet in doing so, they have sought either to maintain the label - or to replace it with another to distance themselves from "misuse." As participatory development has come to draw upon an ever-broader spectrum of methodological possibilities, PRA and its aliases have become just one small component in processes that are multi-faceted, in which participation is not simply about generating knowledge and information, but complex sequences of engagement in different institutional interfaces and spaces. It has become evident that for all the rhetoric about its transformatory promise, the use of PRA for short-cut legitimation exercises and for "facipulating" community consensus does little more than reinsert existing relations of power/knowledge without any semblance of challenge or 
change. The very ambiguity of what a "bottom up" perspective actually entails continues to mask the kinds of uses of participation that Sherry Arnstein (1969) drew attention to in the 1960s: as manipulation and as a feel-good exercise that goes no further.

We suggest that part of the problem is that both critics and advocates have harnessed "PRA" to their own preferred frames of meaning, without countenancing the diversity of practices that are held together under this term. The lack of the "clarity through specificity" that Cohen and Uphoff (1980) called for at the end of another wave of participation in the 1970s, may have served both critics and practitioners well. But it has significant drawbacks. Academic critiques that home in on instances of practice and read from them generalized shortcomings of PRA-in-general may be missing a trick: for every instance a critic lights upon, there is another one that would demonstrate all the qualities perceived to be lacking. It is the polymorphous quality of PRA that evades the critics' gaze. For those whose interest is less academic than practical, the vague and normative character of participation talk hampers any serious attempt to address the quandaries of quality outlined in this paper.

"Clarity through specificity" would avoid the catchall consensus that declares PRA or "participation" a Good Thing, and focus in on how the variant purposes for which PRA might be used can be strengthened. This may involve further experimentation to lend credibility to the uses of PRA's visual methods to generate numbers - dubbed "PartiNumbers"-and provide quantitative data that can serve development planning and impact assessment (Chambers and Mayoux 2004). It has involved the integration of PRA techniques into community organizing, where the use of these tools serves as a stimulus for discussion that is then taken further into action through other methods. It has come to involve generative use of PRA for advocacy, as shown by a recent resource guide that includes a clearly defined ethic with its guidelines for practice (Chapman et al. 2005).

PRA may have disappeared from the headlines of development debate, but it continues to be widely used. The tendency in development is to rush forward into new fads without looking back, to abandon and then reinvent practices. The waves of enthusiasm for participation that have ebbed and flowed over the last century are a good example of the "cultured amnesia" (Cornwall 2006) that characterizes this process of selective forgetting and reinvention. The result is often a failure to think laterally about how experience in one domain might usefully be carried into others because of sectoral silos or policy myopia. The debate on PRA should be 
reinvigorated, not simply to continue debates on questions of epistemology that remain just as salient now as they were in the 1990s, but also to stimulate greater critical reflection on the politics of the practice of participatory methodologies for the generation of knowledge, information, plans and assessments for the new generations of practitioners who have now come to enter the field. As they come to tangle with these dilemmas, some of the lessons from reflection on practice that we share here may be useful.

\section{Acknowledgements}

We'd like to thank the many PRA practitioners who contributed their ideas and experiences to the research project on which this article draws, and to DFID, SDC, and Sida for financial support for our work. We are grateful to Irene Guijt, Robert Chambers, and Rosie McGee for comments. We would also like to acknowledge conversations with Kamal Singh and Ian Scoones that contributed to shaping our analysis.

\section{References}

Absalom, E., R. Chambers, S. Francis, B. Gueye, I. Guijt, S. Joseph, S., D. Johnson, C. Kabutha, M.R. Khan, R. Leurs, J. Mascarenhas, P. Norrish, M. Pimbert, J. Pretty, M. Samaranyake, I. Scoones, M.K. Shah, P. Shah, D. Tamang, J. Thompson, G. Tym, and A. Welbourn. 1995. Sharing our concerns and looking to the future. PLA Notes 22: 5-10.

Arnstein, S. 1969. A ladder of citizen participation. Journal of the American Institute of Planners 35(4): 216-224.

Brock, K., and R. McGee. 2003. Knowing poverty: Critical reflections on participatory research and policy. London: Earthscan.

Chambers, R. 1974. Managing rural development: Ideas and experience from East Asia. Uppsala: Scandinavian Institute of African Studies.

Chambers, Robert. 1997. Whose reality counts? Putting the first last. London: Intermediate Technology Publications. 
Chambers, R. 1992. Rural appraisal: Rapid, relaxed, and participatory. IDS Discussion Paper 311. Brighton: Institute of Development Studies.

Chambers, R. 1983. Rural development: Putting the last first. London: Longman.

Chambers, R., and L. Mayoux. 2004. Reversing the paradigm: Quantification and participatory methods. EDIAIS website. Accessed 6/7/09.

Chapman, J., A. Pereira Junior, L.P. Uprety, S. Okwaare, V. Azumah, and V. Miller. 2005. Critical webs of power and change. London: ActionAid.

Cohen, J., and N. Uphoff. 1980. Participation's place in rural development: Seeking clarity through specificity. World Development 8: 213-235.

Cooke, B., and U. Kothari. 2001. The tyranny of participation. London: Zed Books.

Cornwall, A. 2006. Historical perspectives on participation in development. Commonwealth and Comparative Politics 44(1): 49-65.

Cornwall, A. 2004. New democratic spaces? The politics of institutionalized participation. IDS Bulletin 35(2): 1-11.

Cornwall, A., and S. Fleming. 1995. Context and complexity: Anthropological reflections on PRA. PLA Notes 24: 8-12.

Cornwall, A., and I. Guijt. 2004. Shifting perceptions, changing practices in PRA: From infinite innovation to the quest for quality. PLA Notes 50: 160-167.

Cornwall, A., and G. Pratt, eds. 2003. Pathways to participation: Reflections on PRA. London: Intermediate Technology Publications.

Cornwall, A., S. Musyoki, and G. Pratt. 2001. In search of a new impetus: Practitioners' reflections on PRA and participation in Kenya. IDS Working Paper 131. Brighton: Institute of Development Studies.

Gaventa, J. 1998. The scaling up and institutionalization of PRA: Lessons and challenges. In Who changes: Institutionalizing participation in development, ed. J. Blackburn and J. Holland, 153-166. London: Intermediate Technology Publications.

Guijt, I. 2003. Intrigued and frustrated, enthusiastic and critical: Reflections on PRA. In Pathways to participation: Reflections on PRA, ed. A. Cornwall and G. Pratt, 82-87. London: Intermediate Technology Publications. 
Gwaba, R. 2003. Reflecting on PRA, participation and gender. In Pathways to participation: Reflections on PRA, ed. A. Cornwall and G. Pratt, 88-93. London: Intermediate Technology Publications.

Jassey, K. 2003. PRA from an end-user's perspective. In Pathways to participation: Reflections on PRA, ed. A. Cornwall and G. Pratt, 94-99. London: Intermediate Technology Publications.

Kanji, N. 2003. Mind the gap: Mainstreaming gender and participation in development. Institutionalizing Participation Series. London and Brighton: International Institute for Environment and Development and Institute of Development Studies.

Kapoor, I. 2005. Participatory development, complicity, and desire. Third World Quarterly 26(8): 1203-1220.

Mosse, D. 2001. "People's knowledge," participation, and patronage: Operations and representations in rural development. In Participation-The new tyranny? ed. Bill Cooke and Uma Kothari, 16-35. London: Zed Press.

Mosse, D. 1995. Authority, gender, and knowledge: Theoretical reflections on participatory rural appraisal. ODI Agricultural Administration—Research and Extension Network Paper 44: 569-578.

Moya, X., and S.-A. Way. 2003. Winning spaces: Participatory methodologies in rural processes in Mexico. IDS Working Paper 180. Brighton: Institute of Development Studies.

Narayan, D., M. Walton, and R. Chambers, eds. 2000. Voices of the poor: Crying out for change. Oxford: Oxford University Press.

Pelegrina, W. 2003. Rediscovering a dream: Reflections on PRA experience. In Pathways to participation: Reflections on PRA, ed. A. Cornwall and G. Pratt, 140-144. London: Intermediate Technology Publications.

Pelto, P., and G. Pelto. 1978. Anthropological research: The structure of inquiry. Cambridge: Cambridge University Press.

Pratt, G. 2001. Practitioners' critical reflections on PRA and participation in Nepal. IDS Working Paper122.

Richards, P. 1995. Participatory rural appraisal: A quick and dirty critique. PLA Notes 24: 13-16. 
Shah, M. 2003. The road to Participatory Action Research. In Pathways to participation: Reflections on PRA, ed. A. Cornwall and G. Pratt, 189-195. London: Intermediate Technology Publications.

Thompson, J. 1995. Participatory approaches in government bureaucracies: Facilitating the process of institutional change. World Development 23: 1521-1554.

World Bank. 2000/1. World development report. Washington DC: World Bank. 